\title{
SEXUAL MATURATION IN BULBECTOMIZED FEMALE RATS
}

\author{
N. SATO, E. W. HALLER, ${ }^{*}$ R. D. POWELL AND R. I. HENKIN \\ Section of Neuroendocrinology, National Heart and Lung Institute, Laboratory of Pathology, \\ National Cancer Institute, Bethesda, Maryland, and Department of Physiology, \\ School of Medicine, University of Maryland, College Park, Maryland, U.S.A.
}

\section{(Received 12th February 1973)}

\begin{abstract}
Summary. Vaginal opening was delayed approximately 10 days in rats when olfactory bulbs were removed (bulbectomy) at 6 days of age. No such delay occurred in rats subjected to sham operation at this age or in rats bulbectomized at 20 days of age. Growth of uteri and ovaries in rats bulbectomized at 6 days of age lagged behind that of controls by 10 days and the phasic variation in LH content of the pituitary normally present before vaginal opening did not occur. In all but one rat bulbectomized at 6 days of age and killed at 42 days of age, the delay in vaginal opening was accompanied by the absence of ovarian corpora lutea. These phenomena may be explained by the removal of neural influences normally exerted by the olfactory bulbs on the function of the hypothalamic-pituitary-gonadal axis.
\end{abstract}

\section{INTRODUCTION}

The relationships between olfactory and reproductive function have been extensively studied in man and various other animals. These relationships have been found to be species-, age- and sex-dependent. In animals, they are also related to the manner by which olfactory or brain function is altered. In the adult female rat, nasal installation of silver nitrate or nupercaine (Shelesnyak \& Rosen, 1938) or destruction of the sphenopalatine ganglion (Rosen, Shelesnyak \& Zacharias, 1940) has been reported to prolong dioestrus; in the young female rat, nasal installation of formalin or coagulation or aspiration of the olfactory epithelium has been reported to delay vaginal opening (Orbach \& Kling, 1966). In the adult female rat, however, bulbectomy (Rosen et al., 1940) or electrolytic lesions in the anterior hypothalamus (van Beugen \& van der Werff ten Bosch, 1961) did not alter the oestrous cycle whereas section of the olfactory stalk (Kling, 1964) or electrolytic lesions in the hippocampus in young female rats (Riss, Burstein \& Johnson, 1963) were reported to delay vaginal opening. In the adult male rat, destruction of the medial preoptic anterior hypothalamic continuum either abolished mating (Soulairac, 1963) or produced a decrease in the number of ejaculations

* Present address: Medical Education Program, University of Minnesota, Duluth, Minnesota 55712, U.S.A. 
(Heimer \& Larsson, 1967). In the adult female rabbit, bulbectomy has been reported to reduce gonadal size (Franck, 1966) while electrolytic lesions in the mammillary body produced dioestrus and hypothalamic lesions blocked coitally induced ovulation (Sawyer, 1959). However, earlier investigators had found no effect of bulbectomy in either adult female or male rabbits (Stone, 1925; Brooks, 1937). In the adult female mouse, bulbectomy produced gonadal atrophy though this procedure had no effect on the male (Whitten, 1956). Bulbectomy in the adult female pig resulted in anoestrus (Signoret \& Mauléon, 1962). Little or no effect was observed after bulbectomy or electrical stimulation in the adult guinea-pig (Donovan \& Kopriva, 1965). In the adult cat, electrical stimulation of the olfactory bulbs shortened the oestrous cycle (David, Thiery, Bonvallet \& Dell, 1952). Failure of some investigators to include appropriate control animals in their studies further complicated the interpretation of these already confusing results. Orbach \& Kling (1966) used rats in which only the tail or pinnae were amputated as controls for rats in which formalin was placed in the nose or in which the olfactory epithelium was coagulated or aspirated. These same investigators considered a 4-day delay in vaginal opening (from 38 to 42 days) significant.

These previous studies present a large body of data which often confuse an understanding of relationships between olfactory and gonadal function. The purpose of the present study is to clarify the relationship between olfactory bulb activity and the onset of puberty by determining the effects of bulbectomy on the timing of vaginal opening and the secretion of $\mathrm{LH}$ in rats of specific ages.

\section{MATERIALS AND METHODS}

A total of 138 female Holtzman rats were housed in a light- $(14 \mathrm{hr}$ light/ $10 \mathrm{hr}$ dark) and temperature- $\left(20\right.$ to $22^{\circ} \mathrm{C}$ ) controlled environment. Olfactory bulbs were removed from forty-nine animals at 6 days of age and from nine animals at 20 days of age; sham operations were performed on twenty animals at 6 days of age and the remaining sixty served as intact controls. At operation, rats were anaesthetized with ether, a small portion of the frontal bone was removed, and the dura mater was incised in order to expose the olfactory bulbs. Bulbectomy was performed by suction removal of both olfactory bulbs by direct vision under a dissecting microscope. The cribriform plate was observed in each animal to verify that all connections to the olfactory epithelium had been severed. In all animals, completeness of olfactory bulb removal was demonstrated at autopsy; the brain of each rat was excised and examined to ensure that no gross damage to the frontal lobes had occurred. Sham operation consisted of removal of the frontal bone, incision of the dura mater and exposure of the olfactory bulbs. Following surgery, all categories of animals were randomly distributed to nursing females, each female receiving five young. No special post-operative care was required. Unless killed earlier, all animals were weaned at 21 days of age, housed in individual cages and allowed free access to laboratory chow and water. Body weights were recorded on 6 days of each week. The animals were examined daily for the occurrence of vaginal opening and, once established, daily vaginal smears were taken (Schwartz, 
1964). Animals were killed at 7-day intervals starting at 14 days of age. The number and age of rats killed for which values for organ weights were obtained, and the number and age of rats for which serum LH concentration and pituitary LH content were determined, are shown in Table 1.

Animals were killed between 08.00 and 11.00 hours by exsanguination from the abdominal aorta following ether anaesthesia. The anterior pituitaries, uteri and ovaries were weighed. The ovaries were fixed in a $10 \%$ buffered formalin solution and prepared for examination by light microscopy. Separated sera and anterior pituitaries were snap-frozen in dry ice-alcohol and stored at $-20^{\circ} \mathrm{C}$ until assayed for $\mathrm{LH}$ activity.

Sera from controls and bulbectomized rats were assayed for LH activity by radioimmunoassay according to the procedure of Niswender, Midgley, Monroe

Table 1. Number and age at which control and bulbectomized rats were killed and organ weights and serum and pituitary LH obtained

\begin{tabular}{c|c|c|c|c}
\hline \multirow{2}{*}{$\begin{array}{c}\text { Age } \\
\text { (days) }\end{array}$} & \multicolumn{2}{|c|}{$\begin{array}{c}\text { No. killed } \\
\text { for organ weight determination }\end{array}$} & \multicolumn{2}{c}{$\begin{array}{c}\text { No. examined for } \\
\text { serum and pituitary } L H\end{array}$} \\
\cline { 2 - 5 } & Controls & $\begin{array}{c}\text { Bulbectomized } \\
\text { at } 6 \text { days }\end{array}$ & Controls & $\begin{array}{c}\text { Bulbectomized } \\
\text { at } 6 \text { days }\end{array}$ \\
\hline 14 & 5 & 0 & 5 & 0 \\
21 & 5 & 5 & 5 & 3 \\
28 & 7 & 5 & 7 & 4 \\
35 & 6 & 7 & 6 & 7 \\
42 & 7 & 9 & 7 & 9 \\
49 & 7 & 0 & 7 & 0 \\
56 & 10 & 11 & 7 & 9 \\
63 & 13 & 12 & 8 & 12 \\
Total & 60 & 49 & 52 & 44 \\
\hline
\end{tabular}

\& Reichert (1968). Each sample was analysed in duplicate at two dose levels and the mean was calculated. Means and standard errors were determined for serum LH values for control and bulbectomized groups at the different ages studied.

Anterior pituitaries from controls and bulbectomized rats were homogenized in $1 \mathrm{ml} \mathrm{H}_{2} \mathrm{O}$ and diluted with $1 \%$ egg white (Pentex; PBS-EW) to a concentration of $1 \mathrm{mg} / \mathrm{ml}$. Aliquots were further diluted $(\times 500)$ with PBS-EW for radioimmunoassay. Aliquots were assayed for $\mathrm{LH}$ activity in duplicate at four dose levels and the mean was calculated. Means and standard errors were determined for pituitary LH activity in control and bulbectomized groups at the different ages studied and the significance of difference was determined by Student's $t$ test.

The LH standard used in these assays was a crude aqueous anterior pituitary homogenate diluted with $0.15 \mathrm{~m}$-phosphate buffer $(\mathrm{pH} 7.5)$ in $0.14 \mathrm{M}-\mathrm{NaCl}$ solution containing $1 \%$ (PBS-EW) to correspond to $0 \cdot 17$ times NIH-LH-S ${ }_{1}$ as compared by radioimmunoassay to an identical preparation (B-160) kindly donated by Dr Vernon L. Gay (Gay \& Midgley, 1969). 


\section{RESULTS}

Text-figure 1 illustrates the changes in the parameters measured in controls and in rats bulbectomized at 6 days of age. Although the mean body weight of the control rats was greater than that of the bulbectomized rats after Day 21 (Text-fig. 1a, $P<0.05$ ), the pattern of growth of the two groups was similar. Although vaginal opening in the bulbectomized rats lagged behind that of the controls by approximately 10 days, the body weights of the two groups of rats at the time of vaginal opening were not significantly different (Table 2). The timing of vaginal opening in the rats bulbectomized at 20 days of age and in those subjected to sham operation at 6 days of age and the body weight at which this occurred did not differ significantly from that of the intact controls (Table 2).

Text-figure 1(b) demonstrates that in control and bulbectomized rats, uterine weight did not increase until about the time of their respective vaginal opening. At this time, there appeared to be a three-fold increase in uterine weight followed by no further growth. The pattern of growth of the uterus in the bulbectomized rats was similar to that of the control rats but lagged behind it by approximately 10 days.

Text-figure 1 (c) demonstrates that there was an initial rise in the ovarian weights of the control rats from Days 14 to 28, a subsequent fall at Day 35 and a secondary rise just preceding vaginal opening. Following this, ovarian weight in the controls remained relatively constant. The early portion of the pattern of ovarian growth of the controls was not evident in the bulbectomized rats. Instead, ovarian weight decreased from Day 21 to Day 42, at which time a rise in ovarian weight was observed. This increase in ovarian weight in the bulbectomized rats lagged behind the rise observed in the control rats by approximately 10 days.

As observed in Text-fig. 1(d), the pituitary weights of the bulbectomized rats tended to be lower than those of the controls until vaginal opening occurred, after which time they were approximately equal. Before vaginal opening, there appeared to be a tendency toward phasic variation in the pituitary weight of the control rats whereas, in the bulbectomized rats, a continuous increase in pituitary weight was observed with time.

Serum LH concentration (Text-fig. le) in the bulbectomized rats showed a continuous decline between 21 and 42 days of age. It should be noted that, during this same period, ovarian weight underwent a similar decline whereas there was essentially no change in either pituitary or uterine weights. On Day 56,

\section{EXPLANATION OF PLATE 1}

Comparison of ovarian maturation in representative rats bulbectomized at 6 days of age (left) with appropriate controls (right). The numbers on the left indicate the age of the rats on the day of autopsy. Normal maturation in the controls is shown on Day 42 by an increase in ovarian size and the presence of numerous corpora lutea. In the bulbectomized rats, the morphological features of maturation were not present on Day 42. Morphological features of normal ovarian maturation were observed in bulbectomized rats on Days 56 and 63. Before Day 42, ovaries in the bulbectomized rats also appeared smaller than those of the controls although primary follicles without corpora lutea were present in both. All photomicrographs, haematoxylin-eosin $\times 10$. 


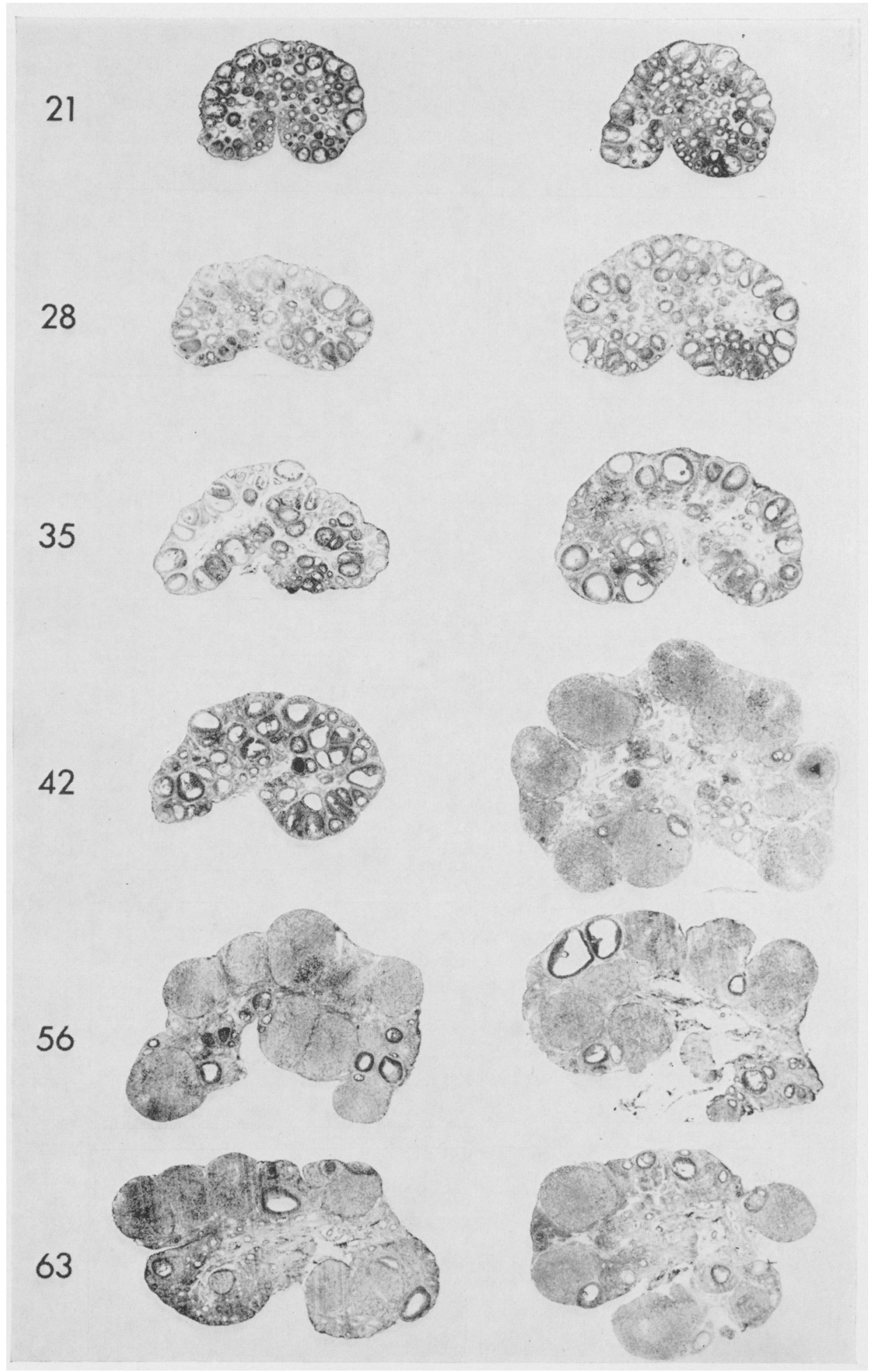

(Facing p. 304) 
PLATE 2
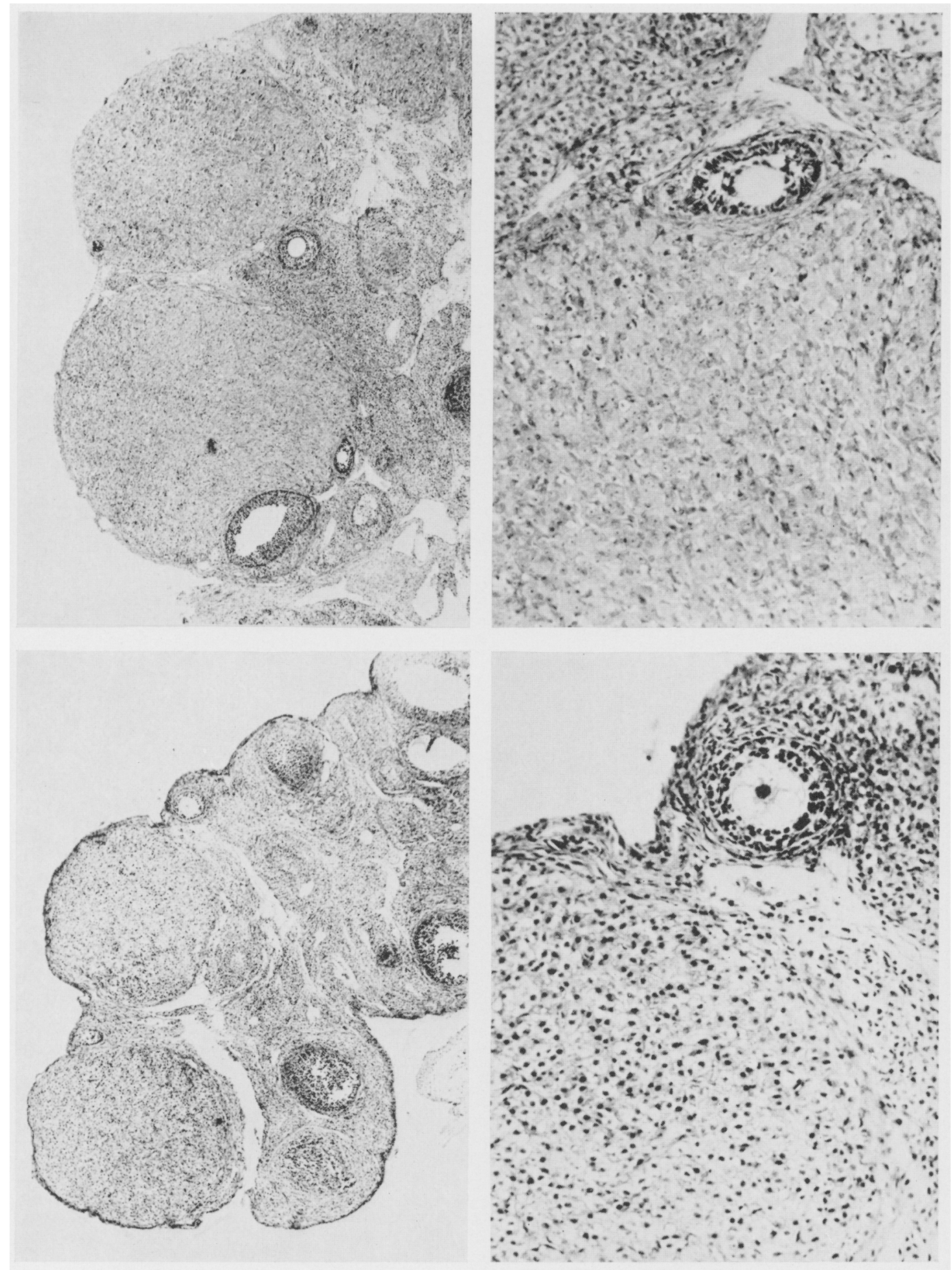

(Facing p. 305) 

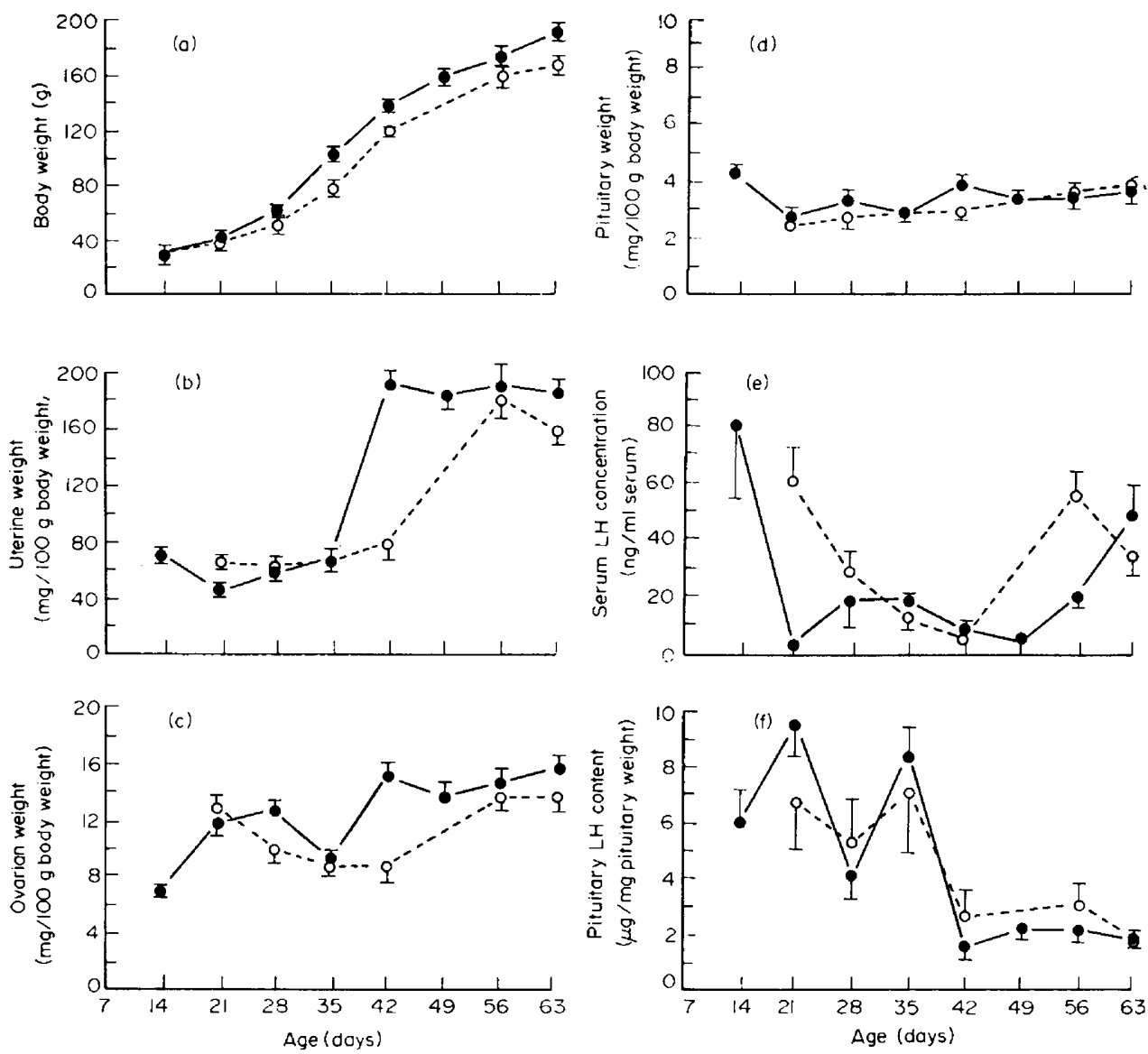

Texr-fic. 1. Comparison of (a) body weight, (b) uterine weight, (c) ovarian weight, (d) pituitary weight, (e) serum LH concentration and (f) pituitary LH content in rats bulbectomized at 6 days of age and in controls. Open circles and lines indicate mean \pm 1 S.E.M. in the bulbectomized rats, connected by dotted lines; closed circles and lines indicate mean \pm 1 S.E.M. in the controls, connected by solid lines.

a pronounced increase in serum LH concentration was observed in the bulbectomized rats. This pattern of prepubertal changes in serum LH concentration in the bulbectomized rats differed markedly from that observed in the control rats. Following high values of serum LH concentration on Day 14 in the controls, values fell to their nadir on Day 21 followed by a rise in serum LH concentration to a level four times that observed at the nadir, a second fall on Day 49 and a second rise on Day 56. This pattern of change in serum LH concentration in bulbectomized rats was similar to that observed

\section{EXPLANATION OF PLATE 2}

Follicular maturation in the one rat bulbectomized at 6 days of age in which vaginal opening occurred by Day 42 compared with that of a representative control animal killed at the same time. The corpora lutea in the bulbectomized rat (bottom) are smaller and appear less intensely stained, suggesting less complete luteinization, than in the control (top). Haematoxylin-eosin. Left photomicrographs, $\times 40$, right $\times 160$. 
in control rats but lagged behind that of the controls by approximately 10 days.

The pituitary LH content of the control rats (Text-fig. If) demonstrated the typical, well known, widely phasic fluctuations previously observed in normal immature, prepubertal animals. By contrast, in the bulbectomized rats, the early fluctuations in LH content observed in the controls were absent, but the pituitary LH content in these rats decreased at the same time as that of the controls even though vaginal opening was delayed by approximately 10 days. Following the respective fall in pituitary $\mathrm{LH}$ content, the levels obtained in control and bulbectomized rats were essentially the same.

Ovarian histological features for representative controls and rats bulbectomized at 6 days of age are shown in Plate 1 for several time periods. In general, ovaries from bulbectomized rats killed on Day 42, or before, were smaller than those of the controls whereas ovaries from rats killed on Days 56 or 63 showed no difference in size. Corpora lutea were present in all ovaries examined from control rats killed on Day 42. These structures were not observed in any ovary

Table 2. Age and body weight at time of vaginal opening in control and bulbectomized female rats and those subjected to sham operation

\begin{tabular}{l|c|cc}
\hline \multicolumn{1}{c|}{ Conditions } & No. of & \multicolumn{2}{|c}{ Vaginal opening } \\
& females & Age (days) & Body weight $(\mathrm{g})$ \\
\hline Intact controls & 37 & $39 \cdot 1 \pm 0 \cdot 6+$ & $127 \cdot 0 \pm 2 \cdot 2$ \\
Bulbectomized at 6 days & 32 & $49 \cdot 3 \pm 2 \cdot 0^{* *}$ & $117 \cdot 5 \pm 4 \cdot 0$ \\
Bulbectomized at 20 days & 9 & $39 \cdot 4 \pm 1 \cdot 5$ & $124 \cdot 4 \pm 4 \cdot 8$ \\
Sham operation at 6 days & 20 & $38 \cdot 8 \pm 1 \cdot 1$ & $120 \cdot 3 \pm 3 \cdot 5$ \\
\hline
\end{tabular}

** $P<0 \cdot 01$ with respect to every other group studied.

$\dagger$ Mean \pm S.E.M.

from control rats killed before Day 42 but were present in all ovaries from control rats killed at 56 and 63 days of age. However, in the bulbectomized rats, with one exception, no corpora lutea were observed in any ovary examined from rats killed on Day 42. The exception occurred in the one bulbectomized rat in which the vagina opened before Day 42. One of the ovaries from this rat contained two corpora lutea which were small, showed relatively pale cytoplasmic staining and appeared incompletely developed (Plate 2). With respect to the number of primary or involuting ovarian follicles, no important differences were noted in controls compared to bulbectomized rats. These follicles were observed in all ovaries examined at all ages in all groups of rats.

Following sexual maturation, as indicated by vaginal opening, normal 4-day oestrous cycles were observed in bulbectomized, intact control rats and those subjected to sham operation as indicated by changes in cell cytology observed in vaginal smears. In rats bulbectomized at 6 days, cyclic oestrus occurred following vaginal opening 10 days later than in intact controls.

\section{DISCUSSION}

These results demonstrate that, in female rats bulbectomized at 6 days of age, vaginal opening was delayed by approximately 10 days compared with controls. 
This delay correlated with the differences noted in uterine and ovarian weights between the bulbectomized and control rats. Once vaginal opening occurred in the bulbectomized rats, the ovarian size and histological appearance and the oestrous cycles could not be distinguished from those of the control rats. Apparently, early bulbectomy in rats results only in a delay in sexual maturation, not in any permanent loss of gonadal function.

The influence of the olfactory bulbs on the rat hypothalamic-pituitarygonadal axis appears to be highly time-dependent. If bulbectomy is performed at 6 or 14 days of age (N. Sato and R. I. Henkin, unpublished observations) a significant delay in vaginal opening occurs but bulbectomy at 20 days of age has no effect upon this phenomenon. Although it is generally agreed that olfactory input to the hypothalamus is of importance to the onset of puberty (Orbach \& Kling, 1966), there has been no previous direct evidence to support this assumption or to provide data about the exact timing of this interrelationship.

The critical point of the effects of bulbectomy on sexual maturation appears to be around 42 days of age, at which time corpora lutea are present in the control rats but generally absent from the rats bulbectomized at 6 days of age. These observations correlate well with the decreased concentrations of pituitary LH and smaller uterine weights, the latter suggesting lack of circulating progesterone in the bulbectomized rats, just as the delay in vaginal opening suggests a lack of oestrogen.

The mechanism(s) by which these changes occur is not clear. Whether high serum LH concentrations during the prepubertal period are required for normal maturation of the ovary is not known. Changes in FSH levels must play an important rôle in these events but information about this hormone in this species is not yet available.

The present results suggest that, in bulbectomized rats, there is loss of some mechanism(s) which controls the pituitary LH content. On the basis of the multiple neural pathways from the olfactory bulbs to the hypothalamus, it seems possible that loss of olfactory input at an early age may affect the rate of maturation of the hypothalamic neurosecretory cells involved with the production or release of LH-RF and/or FSH-RF. This general concept has been considered previously (Orbach \& Kling, 1966) and, in the gilt, bulbectomy has been shown histochemically to interfere with cells involved in secretion of pituitary gonadotrophins (Signoret \& Mauléon, 1962).

Deprivation of light stimuli in the rat (Browman, 1940) or visual stimuli in the bird (Lott \& Brody, 1966) has produced delayed vaginal opening while in the mouse deprivation of the odour of the male has been associated with the persistence of irregular oestrous cycles (Whitten, 1957, 1958). Conversely, the presence of unpleasant, noxious or foreign stimuli, such as overcrowded living conditions for the mouse (Whitten, 1959), excessive noise exposure for the rat (Zondek \& Tamari, 1964; Sackler, Weltman, Bradshaw \& Jurtshuk, 1959; Sackler, Weltman \& Jurtshuk, 1960) or exposure of the female mouse to an alien male (Parkes \& Bruce, 1961), has also been reported to produce decreased fertility and/or smaller than normal ovaries. The noise-exposure studies suggested to some investigators that its influence on the hypothalamic-pituitary- 
gonadal axis was through the inhibition of release of pituitary gonadotrophins (Sackler et al., 1959). Thus, not only the modality but also the intensity of environmental stimuli can influence the timing of the onset of puberty, possibly through their effect on hypothalamic-pituitary-gonadal maturation.

Deprivation of signals from some sensory modalities appears to be more detrimental to gonadal function in females than in males. Bulbectomy in female mice was associated with smaller than normal ovaries and uteri while this procedure had no effect on males (Whitten, 1956). Similarly, inhibition of genital licking and sniffing delayed vaginal opening in female rats whereas this had no effect on male gonadal function (Orbach \& Kling, 1966). Conversely, after peripheral blinding of male rats, smaller than normal testes were found at the age of normal puberty whereas this procedure did not affect females as seriously (Whitten, 1958; Orbach \& Kling, 1966). These findings suggest not only that there is a sex specificity for gonadotrophic releasing factors in the hypothalamus, as previously suggested (Goodman, 1934; Dörner \& Döcke, 1964), but also that specific sensory inputs may differentially affect males and females.

\section{ACKNOWLEDGMENTS}

The authors wish to express their gratitude to Dr C. A. Barraclough in whose laboratory a significant portion of this work was carried out and supported by NIH Grant Number HD 02-138. The authors also wish to thank Mr Ralph Eisenberg for his photographic skill. One of us (N.S.) was a Fellow of the Population Council of New York.

\section{REFERENCES}

BRooks, C. McC. (1937) The role of the cerebral cortex and of various sense organs in the excitation and execution of mating activity in the rabbit. Am. F. Physiol. 120, 544.

Browman, L. G. (1940) The effect of optic enucleation on the male albino rat. Anat. Rec. 78, 58.

David, R., Thiery, G., Bonvallet, M. \& Dell, P. (1952) Effets de la stimulation des bulbes olfactifs sur le cycle sexuel de la chatte. C.r. Séanc. Soc. Biol. 146, 670.

Donovan, B. T. \& Kopriva, P. C. (1965) Effect of removal or stimulation of the olfactory bulbs on the estrous cycle of the guinea pig. Endocrinology, 77, 213.

DörNer, G. \& DöcKe. F. (1964) A sex-specific reaction of the hypothalamo-hypophysial system of rats. J. Endocr. 30, 265.

FrancK, H. (1966) Ablation des bulbes olfactifs chez la lapine en pubère. Répercussions sur le tractus génital et le comportement sexuel. C.r. Séanc. Soc. Biol. 160, 389.

GAY, V. L. \& MidGLEY, A. R., JR (1969) Response of the adult rat to orchidectomy and ovariectomy as determined by LH radioinmmunioassay. Endocrinology, 84, 1359.

Goodman, L. (1934) Observations on transplanted immature ovaries in the eyes of adult male and female rats. Anat. Rec. 59, 223.

Heimer, L. \& Larsson, K. (1967) Mating behavior of male rates after olfactory bulb lesions. Physiol. $\mathbb{E}$ Behav. 2, 207.

KLing, A. (1964) Effects of rhinencephalic lesions on endocrine and somatic development in the rat. Am. F. Physiol. 206, 1395.

LotT, D. F. \& Brody, P. N. (1966) Support of ovulation in the ring dove by auditory and visual stimuli. F. comp. physiol. Psychol. 62, 311.

Niswender, G. D., Midgley, A. R., Jr, Monroe, S. E. \& Reichert, L. E., Jr (1968) Radioimmunoassay for rat luteinizing hormone with antiovine $\mathrm{LH}$ serum and ovine $\mathrm{LH}^{131} \mathrm{I}$. Proc. Soc. exp. Biol. Med. 128, 807.

Orbach, J. \& KLING, A. (1966) Effect of sensory deprivation on onset of puberty, mating, fertility and gonadal weight in rats. Brain Res. 3, 141. 
Parkes, A. S. \& Bruce, H. M. (1961) Olfactory stimuli in mammalian reproduction. Science, $\mathcal{N} . r$. 134, 1049.

Riss, W., Burstein, S. D. \& Johnson, R. W. (1963) Hippocampal or pyriform lobe damage in infancy and endocrine development of rats. Am. F. Physiol. 204, 861.

Rosen, S., Shelesnyak, M. C. \& Zagharias, L. R. (1940) Naso-genital relationship. II. Pseudopregnancy following extirpation of the sphenopalatine ganglion in the rat. Endocrinology, 27, 463.

Sackler, A. M., Weltman, A. S., Bradshaw, M. \& Jurtshuk, P. (1959) Endocrine changes due to auditory stress. Acta endocr., Copenh. 31, 405.

SAckler, A. M., Weltman, A. S. \& JURtshuK, P. (1960) Endocrine aspects of auditory stress. Aerospace Med. 31, 749.

SAWYER, C. H. (1959) Effects of brain lesions on estrous behavior and reflexogenous ovulation in the rabbit. F. exp. Zool. 142, 227.

Schwartz, N. B. (1964) The effects of ovariectomy on pituitary L.H, uterine weight and vaginal cornification. Am. F. Physiol. 207, 1251.

Shelesnyak, M. C. \& Rosen, S. (1938) Naso-genital relationship. Induction of pseudo-pregnancy in rat by nasal treatment. Endocrinology, 23, 58.

Signoret, J. P. \& MaulÉon, P. (1962) Action de l'ablation des bulbes olfactifs sur les mécanismes de la reproduction chez la truie. Annls Biol. anim. Biochim. Biophys. 2, 167.

Sovlairac, M. L. (1963) Etude éxperimentale des régulations hormono-nerveuses du comportement sexuel du Rat mâle. Annls Endocr. Suppl. 24, 1.

STONE, C. P. (1925) The effects of cerebral destruction on the sexual behavior of rabbits. The olfactory bulbs. Am. F. Physiol. 71, 430.

van Beugen, L. \& VAN DER WeRFF ten Bosch, J. J. (1961) Rat thyroid activity and cold response after removal of frontal parts of the brain. Acta endocr., Copenh. 37, 470.

Whitren, W. K. (1956) The effect of removal of the olfactory bulbs on the gonads of mice. F. Endocr. 14,160 .

WhitTEN, W. K. (1957) Effect of exteroceptive factors on the oestrous cycle of mice. Nature, Lond. 180, 1436.

WHITTEN, W. K. (1958) Modification of the oestrous cycle of the mouse by external stimuli associated with the male. F. Endocr. 17, 307.

Whitten, W. K. (1959) Occurrence of anoestrus in mice caged in groups. F. Endocr. 18, 102.

ZONDEK, B. \& TAMARI, I. (1964). Effect of audiogenic stimulation on genital function and reproduction. Acta endocr., Copenh. Suppl. 90, 227. 